\title{
Sickle Cell Intrahepatic Cholestasis with Acute Liver Failure and Acute Kidney Injury: Favourable Outcome with Exchange Transfusion
}

\author{
Prabir Maji ${ }^{1} \cdot$ Rohan Malik $^{1}$ (ID $\cdot$ Rakesh Lodha $^{2} \cdot$ Arvind Bagga $^{3}$
}

Received: 22 April 2019 / Accepted: 22 August 2019/Published online: 13 September 2019

(C) Dr. K C Chaudhuri Foundation 2019

To the Editor: An 11-y-old girl presented with 2 wk of jaundice, right upper abdominal pain and previous history of two episodes of jaundice. Examination revealed markedly deep icterus and hepatosplenomgaly. Laboratory investigation showed evidence of hemolysis (hemoglobin $9.1 \mathrm{~g} / \mathrm{dl}$, reticulocytosis 19\%, fragmented RBCs, Lactate dehydrogenase $1674 \mathrm{U} / \mathrm{L}$, negative direct and indirect Coombs test), liver dysfunction (total serum bilirubin $68 \mathrm{mg} / \mathrm{dl}$, direct $58 \mathrm{mg} / \mathrm{dl}$, Asparate aminotransferase $100 \mathrm{IU} / \mathrm{L}$, Alanine aminotransferase $200 \mathrm{IU} / \mathrm{L}$, Alkaline phosphatase $660 \mathrm{IU} / \mathrm{L}$, prothrombin time - International normalised ratio 1.6) and Acute kidney injury (AKI) (urea/creatinine 52/1.5 mg/dl, microscopic hematuria). Serology for Dengue, Chikungunya, Hepatitis viruses, Malaria and Leptospira was negative. Within $24 \mathrm{~h}$ she progressed to encephalopathy (Grade II), coagulatopathy (INR 2.4), further hemolysis ( $\mathrm{Hb} 5 \mathrm{~g} / \mathrm{dl}$ ), anuria and metabolic acidosis. Considering Acute Wilsonian crises which presents with this constellation of findings (Acute liver failure, Coomb's negative hemolysis, AKI), plasmapheresis ( 2 cycles) and hemodialysis was initiated. Meanwhile, investigations for Wilsons disease were normal and repeat blood smear demonstrated multiple sickle shaped cells. Acute sickle cell intrahepatic cholestasis (SCIC) was considered. Single volume exchange transfusion (EBT) was done. Post exchange HPLC showed $\mathrm{HbS} 6.1 \%$ (both parents had sickle cell trait). Hydroxyurea was started. She gradually improved over next $45 \mathrm{~d}$ and renal and liver function normalized.

Rohan Malik

dr.rohanmalik@gmail.com

1 Division of Gastroenterology, Hepatology and Clinical Nutrition, Department of Pediatrics, AIIMS, New Delhi, India

2 Division of Pulmonology and Intensive Care, Department of Pediatrics, AIIMS, New Delhi, India

3 Division of Nephrology, Department of Pediatrics, AIIMS, New Delhi, India
Acute SCIC is a rare and usually fatal complication of sickle cell disease (SCD) and should be suspected when a patient presents with very high level of conjugated bilirubin and right upper quadrant pain. The progression to AKI, coagulopathy and liver failure is rapid unless timely interventions are instituted and hence the index of suspicion should be high. The pathophysiology is, extensive adhesion of sickled RBCs to endothelium causing sluggish flow, sinusoidal congestion, ischemia, infarction and hepatic dysfunction [1-3]. Exchange blood transfusion has been shown to be beneficial by lowering the fraction of $\mathrm{HbS}$ [4]. However, even after aggressive EBT and liver transplantation, outcomes may be poor [5]. In light of the published poor outcome in SCIC with encephalopathy, liver failure and renal dysfunction, the case is unique with successful outcome with exchange transfusion, Hydroxyurea and hemodialysis.

\section{Compliance with Ethical Standards}

Conflict of Interest None.

\section{References}

1. Costa DB, Miksad RA, Buff MS, Wang Y, Dezube BJ. Case of fatal sickle cell intrahepatic cholestasis despite use of exchange transfusion in an African-American patient. J Natl Med Assoc. 2006;98: $1183-7$.

2. Sheehy TW. Sickle cell hepatopathy. South Med J. 1977;70:533-8.

3. Banerjee S, Owen C, Chopra S. Sickle cell hepatopathy. Hepatology. 2001:331021-8.

4. Ahn H, Li CS, Wang W. Sickle cell hepatopathy: clinical presentation, treatment and outcome in pediatric and adult patients. Pediatr Blood Cancer. 2005;45:184-90.

5. Blinder MA, Geng B, Lisker-Melman M, et al. Successful orthotopic liver transplantation in an adult patient with sickle cell disease and review of the literature. Hematol Rep. 2013;5:1-4.

Publisher's Note Springer Nature remains neutral with regard to jurisdictional claims in published maps and institutional affiliations. 